\title{
Benefits and Challenges of Achieving a Mainstream Market for Electric Vehicles
}

\section{Final Report}

June 2010

Funding provided by:

U.S. Department of Energy

Vehicle Technologies Program

U.S. Department of Energy

Office of Electricity Delivery \& Energy Reliability
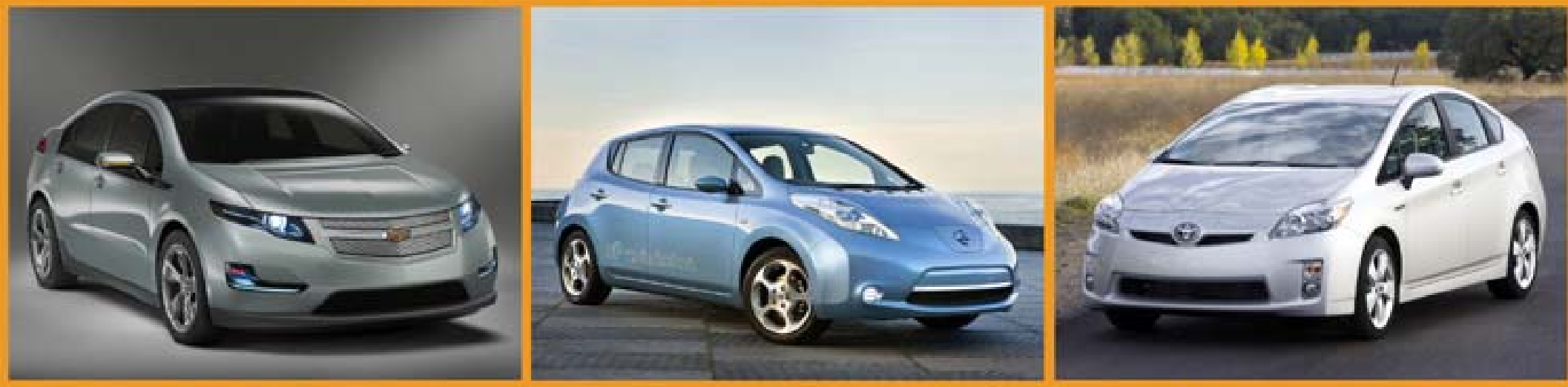

Edward Ungar and Howard Mueller Taratec Corporation

Columbus, Ohio
Brett Smith

Center for Automotive Research

Ann Arbor, Michigan 



\section{DOCUMENT AVAILABILITY}

Reports produced after January 1, 1996, are generally available free via the U.S. Department of Energy (DOE) Information Bridge:

Web site: http://www.osti.gov/bridge

Reports produced before January 1, 1996, may be purchased by members of the public from the following source:

National Technical Information Service

5285 Port Royal Road

Springfield, VA 22161

Telephone: 703-605-6000 (1-800-553-6847)

TDD: 703-487-4639

Fax: 703-605-6900

E-mail: info@ntis.fedworld.gov

Web site: http://www.ntis.gov/support/ordernowabout.htm

Reports are available to DOE employees, DOE contractors, Energy Technology Data Exchange (ETDE)

representatives, and International Nuclear Information System (INIS) representatives from the following source:

Office of Scientific and Technical Information

P.O. Box 62

Oak Ridge, TN 37831

Telephone: 865-576-8401

Fax: 865-576-5728

E-mail: reports@adonis.osti.gov

Web site: $\underline{\text { http://www.osti.gov/contact.html }}$

This report was prepared as an account of work sponsored by an agency of the United States Government. Neither the United States government nor any agency thereof, nor any of their employees, makes any warranty, express or implied, or assumes any legal liability or responsibility for the accuracy, completeness, or usefulness of any information, apparatus, product, or process disclosed, or represents that its use would not infringe privately owned rights. Reference herein to any specific commercial product, process, or service by trade name, trademark, manufacturer, or otherwise, does not necessarily constitute or imply its endorsement, recommendation, or favoring by the United States Government or any agency thereof. The views and opinions of authors expressed herein do not necessarily state or reflect those of the United States Government or any agency thereof. 



\section{Benefits and Challenges of Achieving a} Mainstream Market for Electric Vehicles

Final Report 


\section{Acknowledgements}

Taratec and the Center for Automotive Research project team would like to acknowledge the significant contributions to this effort of Charles Meadows of Taratec and Thomas Gross, an independent consultant. Both contributed in major ways to the thinking and initial testing and evaluation of the influence diagram structuring and the risk/benefit matrix that are the center of this study. Both contributed to the development and testing of the interview guide used to structure the open-ended interviews with the auto industry, utility and public sector participants in the project.

The team would also like to express appreciation for the assistance and input provided in the continuing discussions with the entire Sentech, Inc. project team throughout the studies, particularly the insights and feedback obtained from Richard E. Ziegler and Karen G. Sikes of Sentech.

Finally, the team would like to express gratitude for the continued participation and guidance from the many participants in the informal auto industry/utility industry working group with whom Taratec and CAR have been engaged over the past three years. That informal group's open dialogue around the issues involved in achieving successful plug-in electric vehicle development and commercialization has provided the foundation for the understanding that enabled the conduct of this study. 


\section{Executive Summary}

The Plug-in Hybrid electric Vehicle (PHEV) Market Introduction Study Final Report identified a range of policies, incentives and regulations designed to enhance the probability of success in commercializing PHEVs as they enter the automotive marketplace starting in 2010. The objective of the comprehensive PHEV Value Proposition Study, which encompasses the PHEV Market Introduction Study, to better understand the value proposition that PHEVs (as well as other plug-in electric vehicle platforms - PEVs) provide to the auto companies themselves, to the consumer and to the public at large as represented by the government and its public policies.

As part of the PHEV Value Proposition Study, Taratec was tasked with assessing risks and benefits for stakeholders that play a vital role in the emerging PHEV market. This task includes developing a clear understanding of the benefits of PHEVs to three primary stakeholders - auto industry OEMs, electric utilities, and public policy (i.e., governments) — and of the technical and commercial challenges and risks to achieving commercial success for these vehicles. The goal is to understand the technical and commercial challenges in moving through the transition from the "early adopters" at the point of market introduction of these vehicles to a sustainable mainstream market in which PHEVs and other PEVs represent a normal, commercially available and attractive vehicle to the mainstream consumer. For the purpose of this study, that sustainable market is assumed to be in place in the 2030 timeframe.

The benefits and challenges (risks) associated with each of the three stakeholder perspectives were developed by the Taratec project team based on the PHEV Value Proposition Study Phase 1 results, the team's own broad perspective and direct contact with individuals from each of the stakeholder groups. Those risks and benefits were used to create a "Risk/Benefit" framework that became the principal focus of the analysis. To assess that framework, the Taratec team conducted a series of extensive, open-ended interviews with key individuals representing each of the stakeholder groups. In the interviews, the interviewees were specifically asked to address concerns with regard to the transition from the early adopter to the mainstream vehicle market.

The organizations they represent included Ford, General Motors, Nissan, Toyota, American Electric Power, Consolidated Edison, Duke Energy, DTE Energy, San Diego Gas \& Electric and Southern California Edison.

Benefits to OEMs ranged from medium to high with respect to:

- Customer-driven OEM competitive market position

○ Environmental responsibility

- Economic value proposition (fuel efficiency, reduced maintenance)

○ Reduced oil dependence

- Enhanced vehicle performance

- Impact on OEM ability to meet:

- CAFÉ standards

- ZEV regulations

Supply chain benefits accrued mainly to the battery manufacturers. 
The OEMs did not see PEVs dominating the overall automotive fleet in the timeframe of this study, but instead saw them becoming an important sustainable component of a very diverse fleet that includes all classes of PEVs (EREV, BEVs, PHEVs), ICEs, diesels and HEVs. Most importantly, because of the benefits they have the potential to provide, the participants saw PEVs as an almost essential part of the overall fleet.

With regard to OEM perceptions of technical risks, battery performance was medium to high, as expected. However, OEMs also rank passenger comfort systems as high as they do batteries, likely in consideration of achieving comfort performance without compromising battery effectiveness. The most serious battery risks were associated with battery degradation and production costs.

The most serious perceived commercial risks related to:

- Vehicle performance that meets customer expectations

- Vehicle pricing

- Vehicle trade-in value

- Competition from other technologies - particularly HEVs

- Charging convenience, including availability of convenient public charging.

Utility benefits are perceived to come from the potential to provide a more controllable, flatter load, as well as the potential for increased revenues. Utilities also see benefits from the ability to make even greater use of renewable resources, particularly wind at night. Their most serious risks relate to recovery of infrastructure upgrade investments and an increased potential for distribution system-related outages. The utilities expect that problems associated with installation delays will be largely solved by the time the transition to the mainstream market takes place and view those delays as a lower long-term risk.

Public policy benefits are considered to be high with respect to the ability to meet balance of trade through reductions in imported oil, tailpipe greenhouse gas emissions and national security goals. The most serious risk factor for the public sector was seen to be the potential loss of opportunities for vehicle and battery manufacture to foreign manufacturers.

The risk-benefit analysis is summarized in a map illustrated in Figure 1 for the OEM results. The interviewees perceived the benefits to the OEM to be quite high. They also saw the technical risks as moderate and generally manageable, if the technology development efforts required are forthcoming and successful.

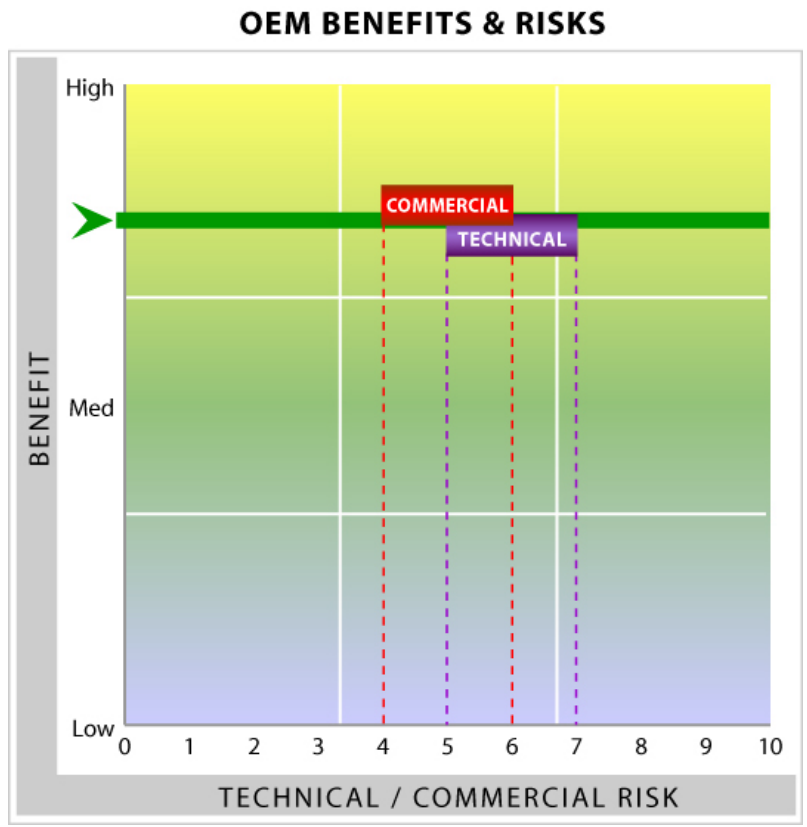


The spread illustrated in the commercial and technical risk assessment reflects the range of perceived risks among the several OEM interviewees. It is interesting to note that the technical risks are perceived to be somewhat higher than the commercial risks, which is not normally the case with advanced technologies. Comments from the OEM participants emphasized the opinion that success in meeting the technical development requirements that they identified, commercial risk would likely be both moderate and manageable.

In viewing the chart, it is important to recognize that it is often argued that government should in general not participate in the low risk and low benefit portions of the chart, where public support offers little additional value to private investment that would normally be forthcoming and result in incremental improvements. The upper right-hand corner denoting high risk and high benefit is the portion of the chart where government investment is generally argued to be particularly valuable to market development, and where private industry participation is inherently more difficult to sustain.

Based on the results of the PEV risk-benefit analysis with the OEM participants, in many ways the electric vehicle risk-benefit profile results shown in the figure lie squarely in what is generally regarded as the "sweet-spot" for government and industry technology collaboration. That conclusion is strongly reinforced when the high public policy benefits that are part of the findings are recognized.

One conclusion to be drawn from the risk-benefit analysis is that public support for PEV development would be most beneficial if focused on those technical and operational issues that both the OEMs and the utilities see as the most important sources of risk for successful PEV transition to a sustainable mainstream vehicle. Those areas are identified in the Taratec riskbenefit study results and recommendations. 


\section{INTRODUCTION}

The Plug-in Hybrid electric Vehicle (PHEV) Market Introduction Study Final Report identified a range of policies, incentives and regulations designed to enhance the probability of success in commercializing PHEVs as they enter the automotive marketplace starting in 2010. The objective of the comprehensive PHEV Value Proposition study, which encompasses the PHEV Market Introduction Study, is to better understand the value proposition that PHEVs (as well as other plug-in electric vehicle platforms - PEVs) provide to the auto companies themselves, to the consumer and to the public at large as represented by the government and its public policies.

In this report we use the more inclusive term PEVs, to include PHEVs, BEVs (battery electric vehicles that operate only on battery) and EREVs ("extended range electric vehicles that combine battery electric vehicles with an internal combustion engine that charges the battery as needed).

The objective of Taratec's contribution to Phase 2 of the PHEV Value Proposition Study is to develop a clear understanding of the benefits of PEVs to three stakeholders - auto original equipment manufacturers (OEMs), utilities, and the government - and of the technical and commercial challenges and risks to be overcome in order to achieve commercial success for these vehicles. The goal is to understand the technical and commercial challenges in moving from the "early adopters" at the point of market introduction of these vehicles to a "sustainable" mainstream market in which PEVs and other PEVs represent a normal, commercially available and attractive vehicle to the mainstream consumer. For the purpose of this study, that sustainable market is assumed to be in place in the 2030 timeframe.

The principal focus of the study is to better understand the technical and commercial challenges in the transition from early adopters to a sustainable mainstream consumer market. Effectively, that translates to understanding the challenges to be overcome during the transition periodbasically the middle years as the second and third generation of these vehicles are developed and come to market. The concern is to understand those things that in the near term would delay that transition.

The study looked at identifying and then quantifying these technical and commercial risks and benefits from three perspectives:

- The auto industry original equipment manufacturers (OEMs) themselves

- The utilities who will provide the electric "fuel" that will fully or partially power the vehicles

- The government, representing public policy interest in PEV success

By clarifying and quantifying these benefits and the technical and commercial risks that could delay the transition to a sustainable mainstream market, the study provides the basis for developing recommendations for government policies and support for PHEV and PEV development. 


\section{ANALYSIS OF PEV RISKS AND BENEFITS: PROJECT APPROACH}

The case studies for the overall Sentech project of which this task is a part are based on a plug-in hybrid electric vehicle (PHEV) projected to exist in the year 2030. That year was chosen during a workshop conducted during Phase 1 of this project. The workshop participants believed 2030 represents a point in time where the PHEV would be a sustainable, mainstream product. It is intended to represent a time frame, by which the PHEV market will be viable and sustainable, rather than an endpoint or a forecast.

By a sustainable, mainstream product we presume that the PHEV will appeal to a significant portion of the U.S. automotive market and will not require substantial government subsidies to be competitive with more traditional but much improved vehicle offerings---including internal combustion engines (ICEs), diesels, or hybrid electric vehicles (HEVs). In this task of the project we use the term PEV to include the PHEVs that were the original focus of the Sentech project, as well as other plug-in electric vehicle (PEV) platforms-i.e., extended range electric vehicles (EREVs) and all-electric battery electric vehicles (BEVs).

For the analysis presented here, the frame of reference is shifted from the PHEV alone to all classes of PEVs.

Between the present day and the end of 2012, there will be numerous plug-in electric vehicle (PEV) launches by manufacturers worldwide. Vehicles reaching the market during this timeframe will embody first-generation technology that is expected to appeal to early adopters and will provide the foundation for mass vehicle deployment. These early-generation vehicles will benefit from government subsidies to consumers as well as subsidies to manufacturers to encourage production in the U.S.

Between 2015 and 2019, we can expect that between 1 and 2 million PEVs will have been sold. Based on previous Taratec analyses, there is good reason to believe that these vehicles will have been sold largely to early adopters with similar demographics and motivations as the early Toyota Prius customers. That previous work also indicated that the early adopters would include fleet operators with specialized usage and purchasing criteria. To broaden customer appeal beyond 2019, the PEV will need to compete with other vehicle offerings on the basis of price, operating costs and performance.

To achieve the cost and performance characteristics believed necessary for sustainable market growth, significant technology advancements will necessarily be required, primarily with regard to batteries, but also with regard to other drive train components, materials for reducing vehicle weight, and accessory electric loads. Experience from the early generation vehicles will provide economic and market incentives for the manufacturers to incorporate new, more advanced technology into production PEVs. The risks that are the focus of this report are associated with PEVs successfully transitioning from the early adopter market to the mainstream light vehicle market.

It is important to recognize that the mainstream automobile market is not homogeneous, but instead represents the sum of a set of sub-markets. For that reason, most of the automotive OEMs with plans for PEV development will be offering a wide range of vehicles with appeal to 
most market segments. At the high end of the market the incremental cost of the electric-drive train is less important than at the lower end of the market. Nevertheless, substantial reductions in the cost of batteries and electric motors will be essential for all market segments. Furthermore, the mass markets associated with the best-selling vehicle classes will be important to achieve the economies of scale necessary to make PEV batteries more affordable.

It is important to note that the different PEV platforms-BEVs, EREVs, PHEVs - are likely to have different value and success in the different market segments. For example, BEVs may be more likely to be targeted at smaller, lighter vehicles than large, heavier ones, especially in the early years. Similarly, larger, heavier vehicles may be better targets for PHEV platforms. Those vehicles may also be better targets for HEVs - especially in the early years of PEV development. Those various platform and vehicle class strategies may well evolve over time-but underscore the importance of technical development, especially for batteries.

Consumers do not typically perform traditional, detailed cost-benefit analysis at the time that they purchase a new vehicle. For example, HEVs have evolved to sell modestly well without a clear economic justification, especially as more producers with more platforms come into the HEV market. As a general principal, to achieve mainstream, mass-market acceptance the electric drive train needs to be able to meet the price, performance and operating characteristics the consumer expects from the competing vehicles and drive trains under consideration. The frequently quoted concept that the consumer may be willing to pay a "premium" for a particular vehicle type is not really an appropriate way to characterize the consumer's choice.

In the perspective of the participants in this study, the individual PEV platforms will have to achieve a balance of cost and performance points that meet the consumer's expectations of those competing platforms. The modeling and analysis conducted by the Sentech team in other tasks in this project suggests that achieving the DOE technical targets will enable the OEMs to produce a price-competitive vehicle in the time frame of the study.

That conclusion provides the basis from which the Taratec/CAR risk/benefit analysis proceeded.

\section{Risk/ Benefit Model}

Risk/benefit modeling of technology development projects was first used by Taratec to analyze the value of DOE investments in technology projects related to improvements in the fuel economy of heavy trucks. The methodology addresses both the risks inherent in technology development as well as the risks associated with commercialization of the technology. In this context, "risks" are defined as the combination of those factors that create challenges that must be met and the likely scale of the impact that they have on achieving success. The methodology implies that achieving the benefits of the technology (both public and private) ultimately depends on being able to incorporate the technology in products that have widespread usage.

Taratec has since extended the methodology and applied it to hundreds of technology projects funded by public and private entities.

The at-risk element of new technology development and its commercialization is the financial resource necessary to achieve success. Automotive manufacturers (OEMs), battery suppliers, and other supply chain participants have invested, along with government agencies, in the 
programs that have enabled the initial PEV market entries. Continuing investments will likely enable the introduction of future mainstream vehicles. Though the prior investment by all parties (sunk cost) has been substantial, it is the risk associated with future investment that is of most concern.

Taratec's risk/benefit analysis is based upon two risk elements, commercial risk and technical risk. Technical risk is the risk involved in the development of a new technology and its embodiment in a new product. Commercial risk is the risk that the technology will be successfully commercialized - in this case the technology will be used in future PEV product offerings and contribute to their success.

In this project, we are focused on the benefits and risks inherent in the transition of the PEV from the early adopter to the mainstream market. Successful transition will require advances in a number of technologies including batteries, electric motors, vehicle materials, braking systems, and accessories such as the customer comfort systems of the vehicle. In the model, we have chosen to address the benefits of the PEV and the technical risks associated with each major technology grouping - for example, batteries. Since not all technologies have equal influence on the outcome, we have used a weighted average of the risks in each technology grouping as a measure of the impact of a particular risk factor. Commercial risks are the market and financial risks to each of the OEMs in deploying mainstream PEV products. As with technical risks, we have applied a weighting factor to each particular commercial risk as a measure of its importance to the ultimate success of PEV products.

From a public policy (governmental) viewpoint, widespread PEV deployment (mainstream success) will result in reduced national dependence on imported petroleum and potentially decreased vehicle emissions of greenhouse gases and other pollutants. There exists considerable public sentiment supporting government concerns over national dependence on imported oil and greenhouse gas emissions. In addition, there is economic benefit to the nation in retaining manufacturing capabilities in the U.S.

The PEV offers the consumer the opportunity to reduce vehicle operating costs by reduced dependence on volatile gasoline prices and reduced maintenance costs. The success of the mainstream PEV will require that the consumer has access to a vehicle that is cost-effective, convenient to charge, meets daily driving requirements, and is fun to drive. It is these benefits to the consumer that define the PEV market.

Successful commercialization of the technologies necessary to achieve a successful family of mainstream PEVs will require that the OEMs and their supply chains be able to obtain a return on their investments consistent with their risks. An acceptable return on investment (ROI) must be achievable in order that the public and consumer benefits can happen. Consequently our focus in evaluating risk will be on the OEMs and their supply chains.

However, we must also address the risk to distribution electric utilities that will supply the electric "fuel" for the PEV vehicles. Those electric utilities will need to continue to supply power reliably and safely to all customers, including electric vehicle charging customers, and will need to recover their investment in the infrastructure necessary to charge the vehicles. Assessing the risks and benefits to the providing utilities is included in this analysis. 
Additionally, we address the public policy (governmental) benefits and risks associated with vehicle electrification.

\section{Risk/Benefit Matrix}

Figures 1 through 4 show a benefit and risk matrix structure developed by the team for each of the three stakeholder sectors. The matrix is intended to depict the principal factors impacting decision-making by the major participants in the PEV mainstream market. These include the vehicle original equipment manufacturers (OEMs) and their supply chains (including battery manufacturers), the electric utilities that provide the electric transportation "fuel," and the public sector (federal, state, and regional).

Each of the major stakeholder sectors benefits from PEVs and is at risk for the investments necessary to achieve commercial success. The factors that are included in these benefit and risk matrices represent a matrix version of an influence diagram - the logic that describes the factors influencing the value of the benefits and risks that ultimately shape the value each stakeholder will achieve from the development of a sustainable PEV market.

As an explanatory note, at a formative stage of the development of the matrix the study team had included the consumer as an independent risk taker and stakeholder. It was concluded, however, that the consumer is better represented as the market that is served by the other participants. The factors that influence the value proposition for each of the stakeholder sectors ultimately matter because in one way or another they shape the development of a sustainable PEV market as consumers accept the PEV as a viable choice among their many automotive technology options.

Figure 1 illustrates the benefits that the development of a sustainable PEV market provides to each stakeholder sector. In the matrix in Figure 1, the stakeholder benefits were ranked as high, medium or low with a numerical ranking of 3,2, and 1 using interviews with representatives of each stakeholder group.

Figure 1: Stakeholder benefit influence diagram

\begin{tabular}{|c|l|l|}
\hline \multicolumn{1}{|c|}{ OEMs \& Supply Chain } & \multicolumn{1}{c|}{ Utilities } & \multicolumn{1}{c|}{ Public Sector } \\
\hline Consumer market position & Improved asset utilization & Economy-Balance of trade \\
\hline Economics & Controllable load & Environment-GHG reduction \\
\hline Environmental responsibility & Flatter load curve & $\begin{array}{l}\text { National security-reduction in } \\
\text { foreign oil }\end{array}$ \\
\hline Reduced oil dependency & Wind utilization & \\
\hline $\begin{array}{l}\text { Availability \& convenience of } \\
\text { charging }\end{array}$ & V2G & \\
\hline Vehicle performance & Revenues & \\
\hline V2B/V2G & Public perception & \\
\hline Fuel efficiency standards & & \\
\hline Meetings ZEV standards & & \\
\hline Battery system suppliers & & \\
\hline New markets \& sales & & \\
\hline Technology leadership & & \\
\hline Non-auto markets & & \\
\hline Other suppliers & & \\
\hline
\end{tabular}


Figures 2, 3 and 4 identify the risks that each of the respective stakeholder group faces in the transition from an early adopter PEV market to the sustainable market for PEVs described in Section 1 above. The challenges that influence those risks are quite different between the three stakeholder communities, but each of these influences creates the risk that the transition to a sustainable PEV market will be delayed or impaired in some way.

The OEM community (Figure 2) faces both technical and commercial risks-technical risks and commercial risks. The technical risks pose the challenge that the PEVs cannot attain the cost or performance targets of various vehicle components necessary to meet the vehicle cost and performance that the market demands, at least not in a timely manner. The commercial risk factors pose a different challenge. They are the factors that influence whether the consumer finds the OEMs' PEV offering attractive in comparison with other options. As a result, these commercial factors also include changing public perceptions and interests, or changes in overall market conditions (e.g., the overall economy).

Only the first and second tier of the factors that influence OEM risks are shown here.

Figure 2: OEM Risk Influence Diagram

\begin{tabular}{|l|l|}
\hline \multicolumn{1}{|c|}{ OEM Technical Risks } & \multicolumn{1}{c|}{ OEM Commercial Risks } \\
\hline Battery & Market \\
\hline Energy density & Vehicle performance \\
\hline Power density & Vehicle design \\
\hline Production costs & Financial (e.g., pricing) \\
\hline Battery degradation & Safety \\
\hline Reliability & Competing technologies (e.g., HEVs) \\
\hline Safety & Environmental priority perceptions \\
\hline Chargers & Overall economy \\
\hline Power control system & Convenience (e.g., charging convenience) \\
\hline Motors and generators & Production costs-supply chain \\
\hline Regenerative breaking efficiency & Warranty costs \& issues \\
\hline Passenger comfort system efficiency & OEM competitive advantage \\
\hline
\end{tabular}

The concept of risk as applied to the utility stakeholders (Figure 3) is different from the OEM community's risks. The OEMs produce and sell vehicles that the consumer must find attractive; if they cannot, the PEV vehicles will fail commercially. Utilities face a different kind of risk. The utilities provide a fueling service, not the vehicle itself. Their services are necessary for the customer to get the value expected from the vehicle purchase, but they stand at risk for the challenge of providing that service in a timely and effective manner. For the utility, the risks are based on the challenges they may have in providing the infrastructure necessary to meet the demands of the new PEV load on their distribution circuits. They also face the risk that added PEV loads on certain circuits create reliability problems (e.g., an increase in the frequency and duration of outages), problems that then limit the public's perception of PEV value and reliability, ultimately damaging the market for PEVs.

Finally, they face the risk that the charging systems necessary to provide battery charging service the customer wants to use (e.g., 240v, or "Level 2" charging) are not installed quickly enough, frustrating PEV buyers and prospective buyers, and once again potentially damaging the pace of 
development of the PEV market. The charging requirements needed include the charging technology at the home or commercial space, the electrical distribution capacity necessary to deliver it, and the electric distribution system technical capability needed to adequately manage the growing levels of charging load. While delivery system infrastructure upgrades are already in progress (e.g., ARRA-funded grid programs), the OEM concern in this area is likely to require ongoing activity and support.

Figure 3: Utility Risk Influence Diagram

\begin{tabular}{|l|}
\hline \multicolumn{1}{|c|}{ Utility Risks } \\
\hline Infrastructure investments needed to upgrade local circuits \\
\hline Distribution system reliability problems \\
\hline Charger installation delays \\
\hline
\end{tabular}

The public sector (Figure 4) represented by the government has specific interests that go beyond the other public policy interests captured in the benefits to both the OEMs and the consumers (e.g., environment, oil dependency, national security) above. The public sector also has interests in the development of viable PEV auto and battery manufacturing industries. Two factors that influence the public sector's broader public policy interests in achieving PEV market success and in the development of viable PEV-related domestic manufacturing are the extent to which there is adequate investment in battery technology development that permits achieving requisite battery cost and performance targets and that there is ultimately inadequate domestic technology leadership that supports domestic as opposed to largely foreign manufacturing.

Figure 4: Public Sector Risk Influence Diagram

\begin{tabular}{|l|}
\hline \multicolumn{1}{|c|}{ Public Sector Risks } \\
\hline Investing too little in battery technology \\
\hline Foreign manufacturing \\
\hline
\end{tabular}

The benefits and risks were estimated for the OEMs and their supply chains, the electric utilities that will supply both power and the distribution system infrastructure necessary for charging, and the public sector.

For the OEMs, risks are further separated between:

1. Technology risks - i.e., the risks associated with meeting technology goals---in this case the goals established by US DOE, and

2. Commercial risks - i.e., the risks associated with achieving commercial success.

To evaluate the benefit and risk elements, the project team (Taratec and the Center for Automotive Research-Ann Arbor) conducted open-ended interviews with a group of OEMs and electric utilities. The OEMs and utilities were selected to represent the range of OEMs with nearterm plans for PEV introduction and utilities that represented a range of regional and market structure differences across the country. Our experience is that open-ended interviews can become conversational and that the elements of the matrix become a checklist for the interviewer to ensure that the important points are addressed. 
In addition, it was felt that one of the members of the Sentech team with long government and DOE service represents government positions and public policy perspectives well. That team member was asked to provide the assessment of the portion of the matrix that represents public benefits and risks. To represent the uncertainty in the public sector risks, he was asked to provide his perspective as a range, analogous to the ranges in the scoring that result from the differing perspectives provided by the multiple representatives for each of the other stakeholder groups.

Given that all of the industry interviewees are currently concerned with the difficulties of introducing first generation products into the market, the team's biggest challenge was to ensure that the interviewees truly addressed the risks associated with the transition of the market from early-adopters to mainstream vehicle buyers. The interviewees appeared to understand the gap between first generation and mainstream product and the early-adopter and mainstream market.

Following the interviews, the benefit/risk matrix was filled in for each stakeholder sector based on the interview results. That is, scores were based on the views expressed by the interviewees, and captured the diversity of views among them. In the analysis that follows, the risk and benefit matrices are shown as ranges to capture that diversity.

For each stakeholder section, the individual risks were given a ranking of high, medium, or low $(3,2$, or 1) representing the importance of each risk factor in influencing PEV market development based on the perspectives provided by each of the stakeholder group participants. The risk factors were then scored on a scale of 1 to 10 (10 being the highest risk) in terms of the actual likelihood that the individual risk factor would actually impact the PEV market development outcome in the timeframe of this study. 


\section{ASSESSMENT RESULTS: THE STAKEHOLDER INTERVIEWS}

The results of the assessment process are presented in the discussion that follows. The results are best described for each stakeholder sector separately. The real value of the risk/benefit analysis comes from understanding the detailed perspectives on these issues provided by the stakeholder participants. To provide that understanding, we present the results of the risk/benefit analysis of each sector. The benefit and risk matrices are shown separately, accompanied by an extensive discussion of the perspectives that the individual participants provided.

\section{Risks/Benefits for the Automobile Manufacturers (OEMs)}

The auto industry will begin the commercial introduction of new plug-in electric vehicles over the course of the next three years. At least ten domestic and foreign auto manufacturers will introduce at least one new PEV platform each in that time window, and some will introduce a second model. The current publicly announced plans for commercial introduction of PEVs are shown in Appendix A in the main body of the Sentech report, but are not reproduced separately here. Some of those models will be produced for the U.S. market alone, while others will also be produced for both U.S. and Asian or European markets, or all three. The auto industry in general recognizes the challenges in introducing a fundamentally different technology to the consumer market. However, they also foresee significant benefits to be derived from presenting the public with a transportation alternative that reduces or eliminates the use of petroleum, and simultaneously reduces or eliminates tailpipe emissions of criteria pollutants and greenhouse gases.

It is important to note that while most major auto companies, domestic and international alike, have PEV entries coming online during the next three years, not all are equally convinced of the likelihood of success in transitioning to a sustainable mainstream. All, however, are committed to the effort needed to make that happen. As will be seen later, they are generally optimistic about the chances for success, but recognize the technical challenges ahead.

\section{Benefits to the OEMs}

The OEM representatives interviewed by CAR for this study in general see medium to high benefits from the introduction of electric vehicles to the market, as seen in the interview results shown in Figure 5. (The width of the bars in that figure illustrates the range of the results among the several interviewees.) Those benefits stem from a variety of sources. 


\section{OEM BENEFITS}

\begin{tabular}{l} 
BENEFITS: Vehicle manufacturer and supply chain \\
OEM competitive position because customer demands it \\
EConomics \\
Minimum liquid fuel consumption/substitution of electricity \\
Reduced maintenance \\
Environmental responsibility - it's cool and green! \\
Reduced oil dependence \\
Availability/convenience of charging \\
Improved vehicle performance \\
V2B/backup power $/ 2 \mathrm{G}$ (?) \\
Helps OEM meet fuel economy \& emission standards \\
Meets ZEV standards for federal \& states \\
Battery system suppliers \\
\hline New market/sales \\
Achieve technology leadership \\
Applicability to non-auto markets (utility \& home storage) \\
Second \& third tier and other suppliers
\end{tabular}

In general, none of the OEM interviewees believe that the PEV will dominate the market, but that the market will continue to have a diverse mix of drive-train technologies-e.g., ICE engines, diesels, hybrid electric vehicles (HEVs), as well as a variety of PEVs. In the same vein, none of the OEM interviewees believe that in the time-frame of this study, any one platform will provide an overwhelming competitive advantage for either their own company or for any one of the class of PEV drive-trains. They believe that competition among EREVs, pure BEVs and PHEVs will continue throughout this period. Further, they believe that since all OEMs will have the technology, there will be no competitive advantage per se between manufacturers.

As discussed above, the sources of the benefits of PEVs to the OEMs come from the ability of the PEV to satisfy the driving preferences of some part of the customer base and from the contribution the PEV can make towards meeting certain specific public policy-driven requirements and objectives.

As shown in the results presented in Figure 5, the PEV platform allows the OEM to meet the consumers' desire for minimizing expenditures for petroleum-based fuels while also reducing their maintenance. The OEMs interviewed here also believe that the characteristics of the electric drive will give them a vehicle with performance characteristics that are attractive to their customers. As the electronic control systems mature, they also noted that the ability of the PEV to provide drive performance that is attractive to consumers is likely to increase.

At the same time, the PEV platform gives the OEM a vehicle that satisfies consumer desires to contribute to societal objectives, including both improved environmental performance and 
reduced dependence on oil. One OEM participant noted that the increased number of PEVs on the road over time also provides an opportunity for the utility industry to further improve the environmental characteristics of the generating fleet-e.g., increased opportunities for renewables, cleaner and more efficient coal plants, etc.

The OEM participants all assumed that by the time period of this study, charging would be convenient.

Generally, the OEMs did not see the use of the PEV as a source of back-up power to the customer's homes or other buildings or the use of the PEV in providing V2G support creating significant benefits.

From their own industry perspective, the OEM participants see significant benefit in the ability of PEVs to help the industry in meeting its own fuel economy standards requirement (e.g., CAFÉ standards) and emission standards, and contributing significantly to meeting "zero emission vehicle" (ZEV) requirements as they develop in this timeframe. One OEM participant noted that the PEV was "essential in meeting industry emissions regulation," and that PEVs may well become literally a required part of the overall emissions strategy. Including PEV technology in their portfolio of drive-train options gives the individual OEM company a vehicle that contributes to meeting fuel economy, emissions and ZEV public policy requirements.

When considering the benefits to their suppliers, the OEMs saw significant benefits accruing to the battery suppliers through the creation of a major new market and generating significant gains in sales, while giving the battery makers an opportunity to make significant gains in their technology leadership. The OEMs did see at least some benefit to the battery suppliers from the opportunity to make some gains in creating new markets for both utility and consumer use of PEV battery technology.

\section{Risks to the OEMs}

As discussed earlier, the OEMs face two very different sources of risks in achieving the sustainable market for PEVs that is the subject of this report - technical risks and commercial risks.

The scores and ratings shown in the chart in Figure 6A combines both the OEM participants' individual perspective on the relative importance of each factor considered in the analysis, the likelihood that the individual factor will be overcome, and the likely importance of the outcome. 


\section{OEM TECHNICAL RISKS}

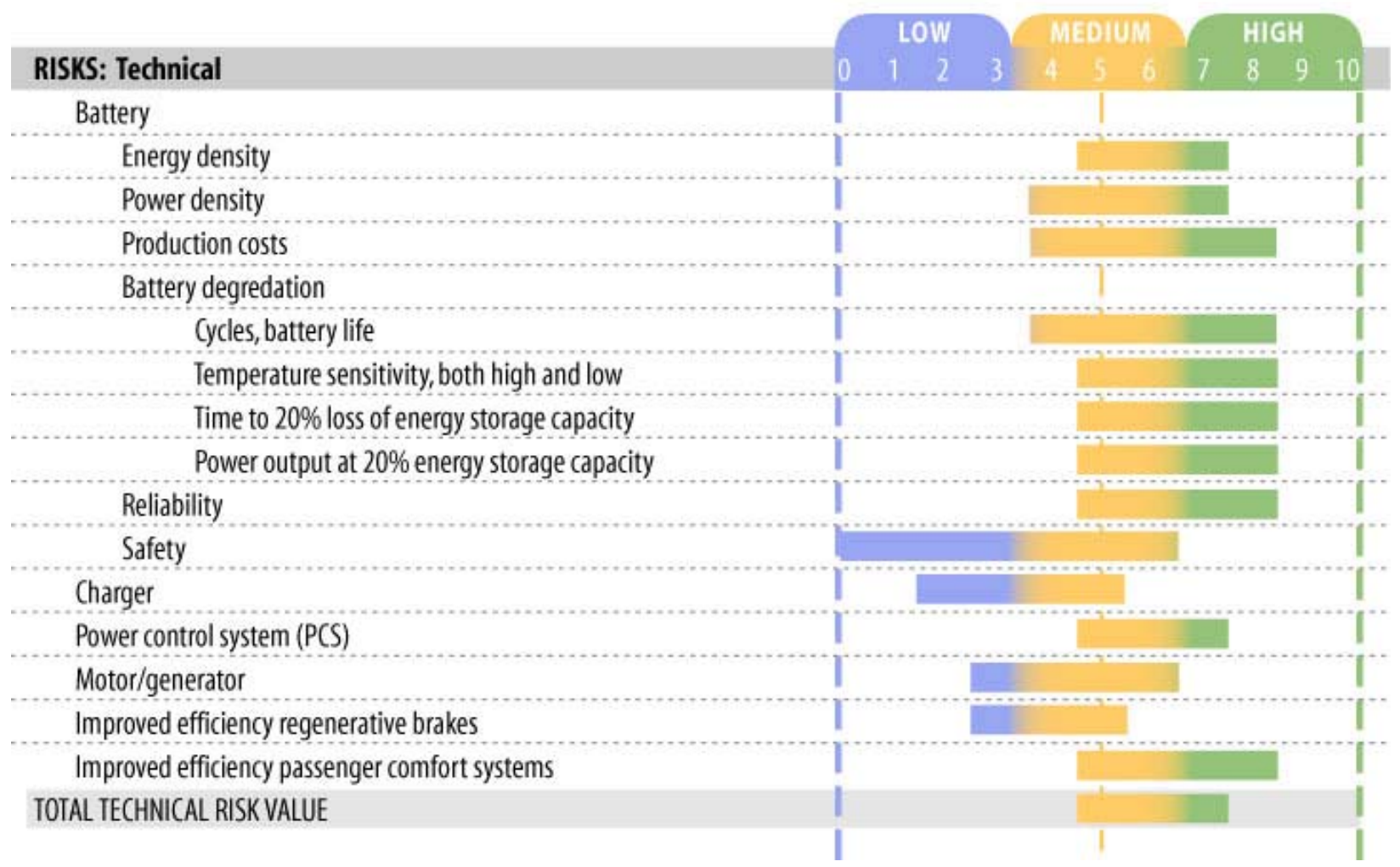

The technical risks to the OEMs are influenced by the battery, the charger, and the power control system, as well as by the other parts of the electrical system generally. Of these, the battery system and its several attributes tended to dominate the OEM assessment. It is important to note the comment made by several participants that in spite of the importance of the many batteryrelated factors influencing the successful transition of the PEV to a sustainable market, none of them are so significant that they cannot be overcome with technology advancement and time. As one participant noted, ICE technology has been developed over 100 years.

Among other things, both battery and power-train electronics are likely to see a development pattern quite different from the classic pattern of development of ICE power train and ICE manufacturing, which often takes many years to evolve. Battery and power electronics may well see a more rapid evolution, more similar to the pace of development that has characterized electronics. While the pattern and pace of development is not likely to be as rapid as the often referenced "Moore's Law" in the chip industry - with steady advances in performance and steady decreases in costs at the same time - it is of a different character than the auto industry has traditionally experienced, and may proceed at a more rapid pace, with significant implications for PEV technical evolution.

Most of the technical factors influencing overall battery performance risks were given almost identical risk ratings. Individual OEM participants tended to call out energy density (affecting driving range both directly and indirectly through vehicle weight reductions), production costs 
(affecting price points), and battery cycle life and overall reliability in the consumers' hands under real-world driving conditions as particularly worthy of comment and attention.

In general, the OEMs did not perceive safety to be a significant source of risk in the time frames of this study. Similarly, they did not rate the charging system in general as a significant source of technical risk.

All of the OEM participants paid particular note to several less obvious technical issues as potentially significant sources of technical risk: the PEVs' power control systems (PCS), which provide opportunities for significant technical improvement, improvement that has the potential to alter both the overall use of battery energy and power (and therefore influence driving range), and improved efficiency in passenger comfort systems which will rely on the use of the battery's energy, not an engine, thereby drawing down battery energy and reducing driving range. As with the battery-related influences of technical risks, the OEMs believe that the opportunities for technical advances in these and other areas are significant, and that performance improvements will go forward in the timeframe of this study.

The commercial influences of risk to PEV market sustainability that the OEM participants pointed to included a set of market-related factors, production costs, and things that might affect vehicle warranties (and hence future resale value). Figure 6B shows the OEM participants' evaluation of those factors. Virtually all of those factors were rated as moderately important overall. 
Figure 6B: OEM Risk Analysis-Commercial Risks

\section{OEM COMMERCIAL RISKS}

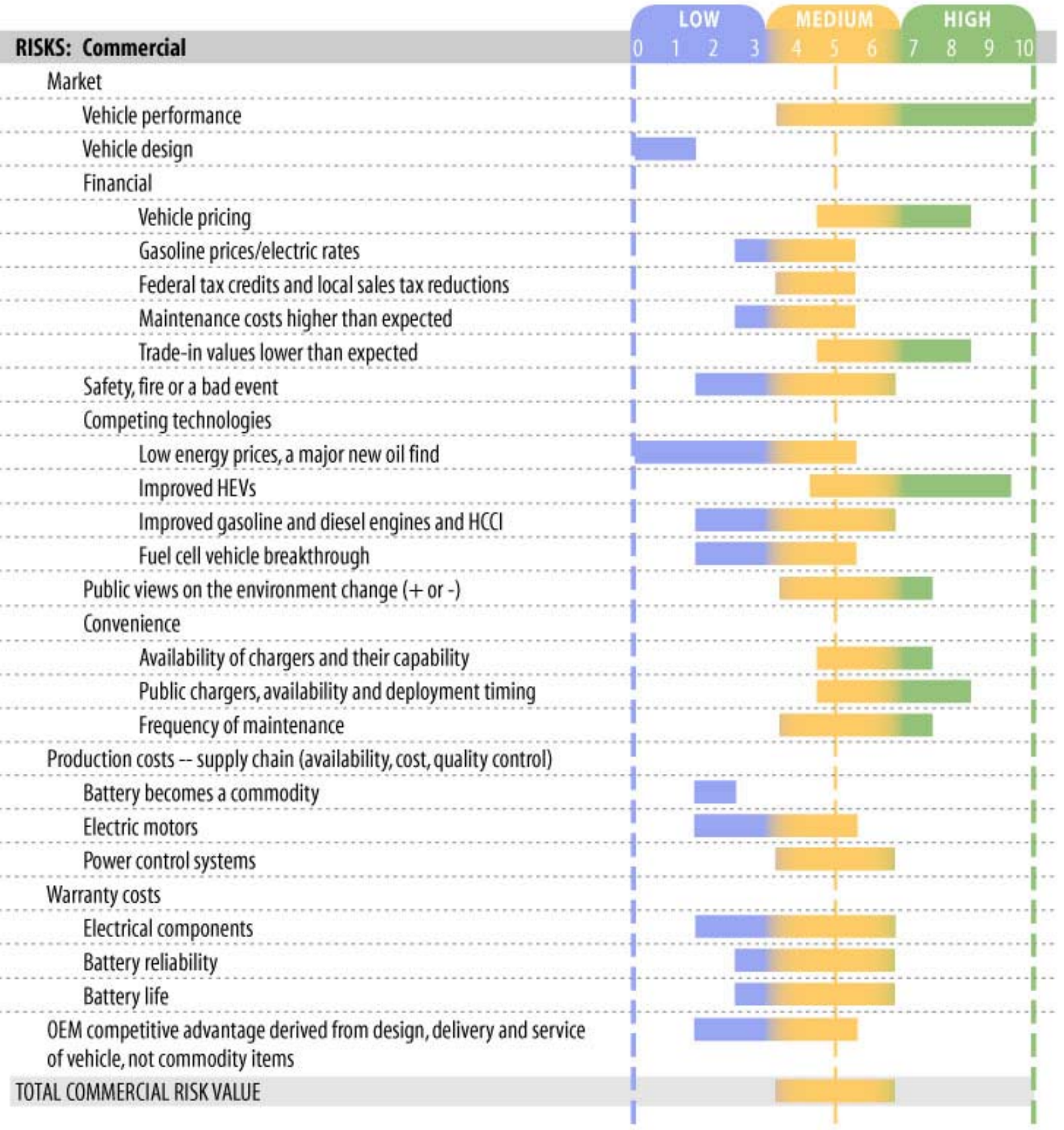

The most significant market-based influence of commercial risk is overall vehicle performance - the ability to meet consumer expectations overall, including performance, durability, maintainability - while at the same time meeting cost/performance expectations. The participants pointed to the very large costs of development of the PEV technology overall and with respect to battery technology in particular. The challenge they pointed to is the business challenge of investing in and meeting customer performance and cost/performance expectations. 
Figure 6B illustrates that point clearly. In that Figure, the three highest market-based, commercial risk factors are vehicle performance, vehicle pricing, and residual value of the vehicle (trade-in). The OEMs also noted that over the timeframe of this study, improvement in one particular class of automotive technology competition - the hybrid (HEV) platform - does have the potential to create significant commercial, market-place risk for the PEV commercial success.

The only other set of factors influencing market-based risks for PEV sustainability come from convenience: the consumers' perception that electrical charging (i.e., fueling) is truly convenient. Availability of charging and the convenience and timing of public charging all shape the ability of the PEV to deliver on its overall value proposition to the customer: the ability to dramatically reduce oil consumption and spending and significantly reduce vehicle tailpipe emissions by using electricity for a high percentage of driving miles, or for all driving miles in the case of pure battery EVs. As the OEM participants noted, without assured, convenient, reliable, speedy charging, the ability to deliver on the basic value proposition fails.

As shown in Figure 6B, the other sources of commercial risk to PEV market success were generally ranked as moderate or even low. Over this time period, production costs of the battery and electrical equipment were perceived to be only a moderate contributor to risk, while the factors affecting warranty risks were ranked even lower.

One comment made by the OEM participants is not evident in the commercial risk component of Figure 6, and is worth noting. From an OEM's commercial and business risk perspective, the PEV technology has a relatively unique attribute. As noted, PEV technology has been and is likely to remain relatively expensive to develop, since it represents a major new technology advance, rather than an incremental improvement over existing platforms. At the same time, the electrical character of the PEV means that expected improvements in the technology may quickly obsolete earlier generations of the PEV platform, leaving little time to recoup investments. Those OEMs who do not obsolete their own technology may well find their platforms quickly made obsolete by others.

As noted above, for all automotive technology, resale value is important to the buyer. The ability of electrical technology to advance quickly, rendering early versions rapidly obsolete, has the potential of reducing resale values for the consumer. For a vehicle that is likely to remain relatively expensive through a good portion of the transition period considered in this study, the pace of technology change and obsolescence with its negative impact on resale value may pose an additional source of commercial risk for the OEMs.

\section{Risk/Benefits for Utilities}

For the first time since the earliest days of the domestic auto industry, electric utilities will become the provider of transportation "fuel" - electricity — to the motoring public, both consumer and commercial. Electric utilities will provide all or part of the energy that will power the PEVs.

Supplying energy for the PEVs can be divided into two separate functions: providing the supply of electric energy coming from generation and transmission facilities (the generation function) 
and delivering that energy to the customer's premise (focused largely on the distribution system portion of the energy delivery system).

PEV loads have attributes in common with loads coming from other appliances and commercial and industrial uses of electricity. There is a load of a certain size, and the demand for that load will be instantaneous and will persist for some period of time, here measured in hours rather than minutes. That said, there are characteristics of the PEV load that make it different from other loads.

PEV loads are relatively large in comparison with other appliances, and will likely be powered at a higher voltage - e.g., 240v, like a clothes dryer, rather than the typical $120 \mathrm{v}$ of most other household appliances. The loads are likely to be continuous for a period of hours (e.g., 4-to-6 hours at 240v, not the 20 to 40 minutes more typical of a clothes dryer. And PEV loads represent a large, continuous new load being placed in a neighborhood where energy requirements and use profiles are long established, and where the distribution system has been designed to serve efficiently and reliably, with adequate delivery capacity.

The utility industry has recognized the importance of the emerging PEV market to its customers and to public policy, and has repeatedly said that it wants to facilitate that market, not impede it. It also believes that it needs to be reliable and efficient from the very beginning of the PEV market development, so as to aid in public acceptance and assurance with regard to the PEV vehicle itself.

Although it does not intend to develop or market the PEV, the utility industry sees a number of benefits deriving from PEV market success, but is also aware of a number of important risks and challenges that the PEVs present.

\section{Benefits to the Utilities}

All of the utilities participating in this study represent regulated distribution companies, and most of the individual participants are associated with the distribution or energy delivery part of their companies. Most of the participating utility companies, but not all, include a generation function in their business.

A utility's revenue stream generally includes a delivery component that compensates it for the capital expense and maintenance required to provide electricity delivery service to its customers, as well as a component that represents compensation for the cost of the generation associated with the electric energy the customer uses. In all cases the electric generation component includes the cost of generation purchased from other providers.

All of the utility interviewees see the benefits to their companies accruing from successful PEV deployment as medium to high. They see those benefits developing over time, and coming into use during a time when both their generation fuel mix and their energy delivery technology will be changing. As a result, some of the sources of the benefits they expect to see will come in somewhat non-traditional ways. 
Figure 7 presents the utility PEV benefit analysis.

Figure 7: Utility Benefit Analysis

\section{UTILITIES BENEFITS}

$\begin{aligned} & \text { BENEFITS: Utility/grid operator } \\ & \text { Improved asset utilization } \\ & \text { Controllable load } \\ & \text { Flatter load curve/wind utilization }\end{aligned}$ V2G ...maybe?
Revenues
Public perception -- rate cases

Perhaps the most important source of benefits from PEVs that the utilities identified was the likely improvement to asset utilization in both the energy delivery system and the generation system. The loads on the utility generating and distribution systems vary throughout the day and evening, from weekday to weekend, and from month to month. On a daily basis, loads will typically become quite low during the middle of the night, and then grow slowly into the morning hours until they grow more rapidly to a peak, generally in mid-afternoon when temperatures are highest and commercial and industrial activity is at a peak. The loads drop again during the evening and reach the bottom of the load curve at night.

Distribution system load patterns are somewhat different in residential areas, peaking in early evening when residents return home and turn on heating or air conditioning, televisions and cooking equipment. Thus, there is diversity between the peak loads to serve the commercial versus the residential customers. In more rural and generally winter-peaking areas, the residential and system peaks may both occur in the evening, with greater lighting and heating loads coming on.

These variations in daily, monthly and seasonal load patterns have required the design of generation and distribution systems that have the capacity to meet generation and distribution peak requirements. As a result, utilities have had to design their systems with excess generation and distribution system capacity to be able to serve the highest part of the generation and distribution peaks. The result is that the systems are under-utilized for many hours of the day and year.

Adding a PEV charging load that comes on during the evening and that uses a significant amount of electricity means that the use of the generation and distribution systems will become more uniform over time, leading to higher rates of utilization, generally improving system operations and spreading the capital cost of the system over a larger energy usage, and generally reducing some operating and maintenance costs. The interviewees see improvements to asset utilization as a very significant benefit of PEV market development.

The utility participants also believe that PEV charging will generally be a controllable load. In the time frame of this study, they believe that the use of $240 \mathrm{v}$ charging will be widespread, 
enabling PEV charging to be controlled in terms of charging times. Controllability of load provides utilities with the ability to time the loads to meet both distribution and generation system operating needs. Although load management is generally technically available and feasible, it is not widely used today at the residential level. Today most loads, especially at the residential level remain uncontrolled - the timing of load is determined strictly by the customer.

To the extent that PEV charging becomes widely adopted, the advent of a significant amount of controllable load is widely viewed as a very attractive benefit to utility operations by the participants.

Many states have adopted renewable portfolio standards (RPS) that require a specified percentage of electricity purchased by the distribution utilities to have been generated from renewable sources. There is often a mismatch between several forms of renewable generation and peak electrical system loads. For example, depending on location (e.g., western coastal states, or areas along eastern ridges or along lake margins), wind patterns often peak at night, while most electrical loads peak during the day. To the extent that electric vehicle charging loads can occur during the nighttime, they can consume wind generated electricity that the utilities might otherwise have to reject or have to direct to utility-controlled storage, which helps utilities meet RPS standards.

The interviewees in this study placed a high degree of importance on the ability to increase their use of wind-generated electricity in meeting RPS requirements.

While there has been extensive discussion in the literature about the potential for "V2G"applications for electric vehicles (e.g., the use of the electric power and energy stored in an electric vehicle's batteries to support the operation of the electric grid), the utility participants in this study did not believe that V2G applications would become practical during the timeframe of this study, and generally rated its benefit to the system as low.

The utilities also rated the benefits from potential new revenues as medium to high. Utility rate regulation provides funds to recover both capital and operating expenses for their distribution, transmission and generation costs from either their own assets or purchased power, and permit a rate of return on their capital expenses. Those revenues come from the collection of rates allowed as the result of rate case decisions after review and approval by the appropriate utility rate regulatory commission. The revenues are then collected from rates charged on a per $\mathrm{kWh}$ usage basis. Since the utilities' revenues and actual rate of return are dependent on sales, a "new" load that increases energy sales - especially one that does not require construction of new generation or transmission capacity - is profitable to the utilities.

\section{Risks to the Utilities}

Although the growth of the PEV load poses some clear risks for utilities, the utility participants viewed those risks as moderate and generally manageable, given the timeframe of this study. In particular, they felt that the risks might actually be greatest during the introductory and early market growth phases of PEV development. Figure 8 summarizes the utility risk analysis results. 
Figure 8: Utility Risk Analysis

\section{UTILITIES RISKS}

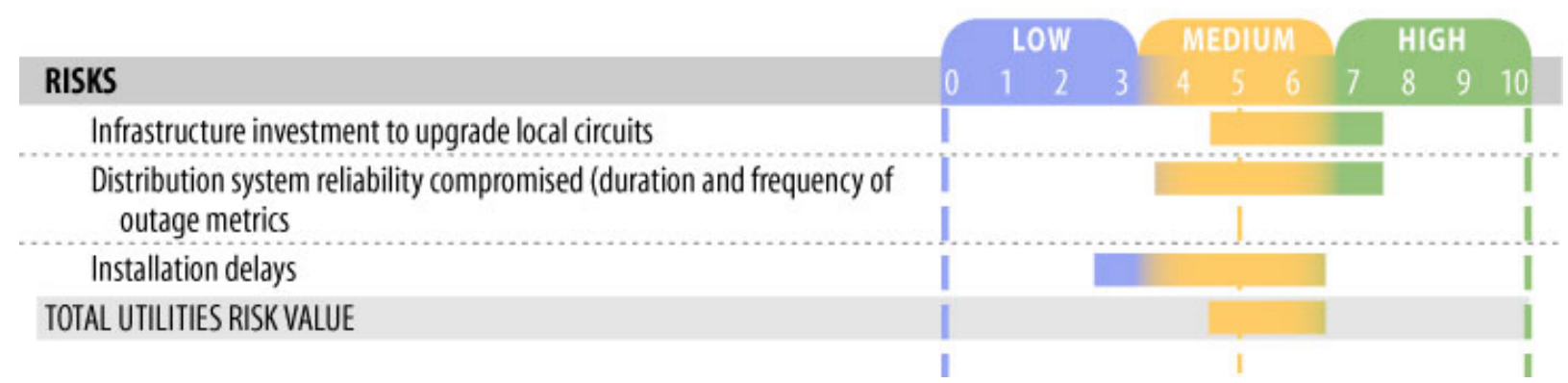

As already noted, distribution systems have been designed to serve specific types and patterns of electric loads. Additions of PEV charging requirements may exceed the design specifications of the local distribution grid in residential areas, if many PEVs are plugged in and charged at the end of the afternoon commute, when residential loads now tend to peak. Without controlled charging, this would likely require costly additions to the delivery capacity of that specific section of the grid.

The greatest single concern expressed by the interviewees was related to their recovery of system upgrade costs, particularly during the early years of the "transition" phase of the development of the PEV market, when the numbers of PEVs may be growing fairly rapidly, and appearing in a growing number of communities. They generally expressed the concern that while the "obligation to serve" would ultimately permit them to recover those costs, they saw revenue risk in the potential mismatch between their capital plans at any point in time and the actual location of new consumer PEVs. The ability to change capital upgrade plans in the short run is limited. Several participants saw a potential risk of having to deal with local PEV "hot spots" that could spike capital requirements and construction plans in this "transition" time frame. That disruption could in turn create difficulties in cost recovery, given the speed of the ratemaking processes in their individual states.

They generally felt more comfortable that this potential rate recovery exposure would be significantly reduced over time, as experience grew with PEV charging locations and requirements and as system upgrades continued to be established to accommodate these new loads.

By contrast to consumer vehicles, they generally saw commercial fleet PEV deployments as requiring very specific charging requirements that would be accommodated with customer planning and customer charges under normal commercial rates and contracts.

The utility participants did express the concern that during the early years of the transition towards a sustainable market, the uncertainty in predicting where early PEV sales would be concentrated might result in a short-term deterioration of local distribution system reliability (the frequency and duration of customer outages) or power quality (the ability to maintain delivered voltage within limits). To the extent that several consumers along a given circuit or served by a specific transformer purchased PEVs at the same time (what the participants tended to describe as PEV "hot spots"), the utility could run the risk that some transformers or circuits could 
become overloaded. Outages could occur at those points, and upgrades would be required that had not been previously planned.

To the extent that the utilities were informed of new PEV purchases, equipment overloads at these prospective "hot spots" could be avoided. They expressed the concern that consumer privacy concerns might limit their ability to be informed of the imminent arrival of additional PEV loads, and hoped that mechanisms might be developed to allow the utility to be informed of new purchases by some combination of the PEV auto dealer, the consumer, or the vehicle registration process.

The utilities believe that as their predictive modeling of PEV purchases and loads improves, as distribution system upgrades are put in place where needed, as PEV charging load management becomes firmly established and as experience with PEV charging patterns becomes more widespread by utilities and customers alike, these initial reliability challenges and risks will disappear.

The interviewees were not overly concerned with issues related to home charger installations beyond the transition period, although they frequently expressed concern about the speed of developing smooth implementation during the early stages of the transition. They felt that there would ultimately be coordination between the car dealer and whoever was going to install charging systems in the home. This coordination would strengthen as charging equipment became generally standardized. They were also not overly concerned with possible damage to their own reputation if the process with car dealer did not go as planned.

As a result, they viewed installation challenges as a transition issue that would also tend to disappear over the time frame of this study.

The utility participants spoke to several issues that relate to PEV charging and utility infrastructure. They indicated that although those issues are widely discussed, they did not see those issues presenting specific risks to their ability to support PEV development. The utilities' perspective on these issues is worth including here, even though they do not affect the utility risk analysis.

The utilities expressed general support for the distribution system technology upgrades associated with "Smart Grid" projects, but in most cases felt that "Smart Grid" would not be fully deployed across their entire service areas. They also noted that in general across the industry, implementation of "smart grid" technology is likely to be a long, slow process, and that for most utilities, PEV market development is likely to significantly precede very wide-spread "smart grid" deployment. Some of the utility participants did note that there are exceptions to that trend, and that their systems were proceeding with "smart grid" development quite rapidly (e.g., the California utilities).

Somewhat contrary to popular reporting, they did not feel that "smart grid" is necessary for PEVs charging management. While they do see and greatly value the benefits in controlling PEV charging in general, they note that charging load management is quite feasible with current technology. At the same time, they pointed out that the presence of "smart grid" technology would be very beneficial to PEV load management. 
Several of the utility participants expressed a concern with regard to PEV charging load management. Most utilities believe that they will have the technical capability to control whether vehicle chargers are on or off, with or without "smart grid" technology. However, a number of the interviewees believe that they are likely to be restricted by their regulators and only be able to turn off chargers with the permission of the vehicle owners or under very specific rate structures. Some also expressed the concern that that ability might also be limited by OEM warranty requirements. Further, some participants indicated that they may only be able to offer either an interruptible or time of day rate for PEVs to commercial and industrial customers, depending on rules applicable within their individual regulatory jurisdictions.

Regardless of the regulatory issues, all of the interviewees believed that in the timeframe of this study (the "sustainable" market period), charging would likely take place primarily in the nighttime hours and most often with 240 volt, Level 2 chargers.

With regard to public charging, the interviewees did not envision that the utilities had an adequate mechanism to recover the installation costs, and saw a high risk that utility participation in public charging installations would result in "stranded asset" investments to the extent that the chargers were not heavily used. They felt that the chargers would most likely have to be installed by municipalities or the private sector. They also saw little benefit in attempting to assign the electric costs back to the vehicle owner's home utility bill, whether the charging takes place within or external to the owner's home utility service territory.

As one interviewee noted, "It would cost us a dollar to process a 10 or 20 cent transaction." The interviewees sensed no desire on the consumer's part to pass the bill back to their electric bill, nor any barrier to simply putting the transaction on a credit card or other third-party billing system. Their conclusion was that the transaction should be kept simple from the consumer's perspective and should not add to the utility's back-office data processing complexity and costs.

As reflected in Figures 7 and 8, the utilities involved in this effort viewed the overall risks associated with the PEVs as moderate in the timeframe of this study, while they saw very specific and significant benefits from PEV deployment on their system (e.g., the ability to absorb a greater quantity of renewable generation).

\section{Risk/Benefits for the Public Sector}

The benefits to the public sector- "government benefits"-stem from the ultimate achievement of public policy objectives. The risks to the public sector come from those factors that influence the ability of the OEMs' PEV marketplace to succeed at a level that permits the public sector to attain those goals.

The earlier phases of this study used input from public workshops and from the first regional case study to develop a framework for identifying public sector benefits of PEV market development. Recognizing that framework, the Taratec/CAR team used both its own transportation sector public policy expertise and experience, together with direct input from an independent public policy consultant - a retired senior Federal government leader - to represent public sector perceptions and assessments regarding the public policy benefits of PEVs, and to assess the most important sources of public policy-specific risks in achieving the development of a sustainable PEV market in the timeframe envisioned in this study. 


\section{Benefits to the Public Sector}

The results of that evaluation are shown in Figure 9.

Figure 9: Public Sector Benefit Analysis

\section{GOVERNMENT BENEFITS}

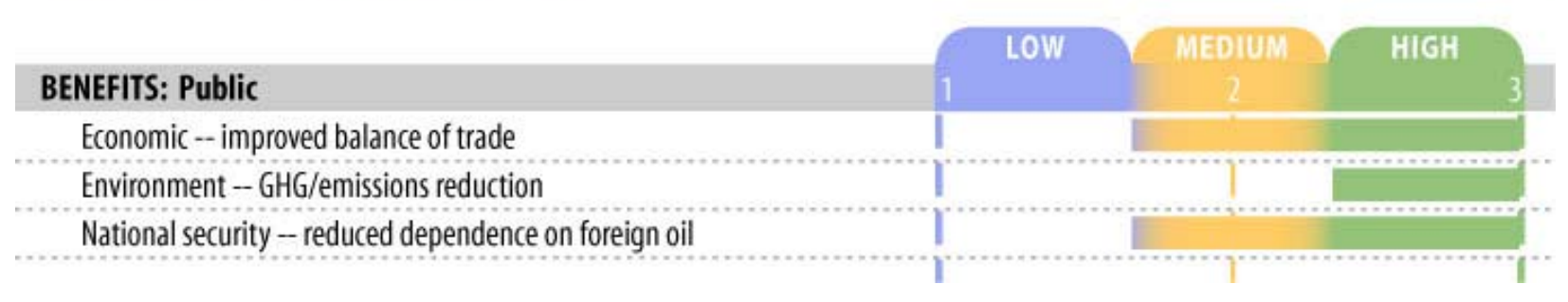

The three major areas of public policy to which PEVs contribute highly are:

1. Economic - the reduction in imports of oil with the resulting improvement in the balance of trade,

2. Environment - the reduction in the contribution of the transportation sector to the emission of greenhouse gasses (GHGs), and

3. National Security - the reduced dependence on foreign oil.

From the public sector public policy perspective, the virtually unique benefit of PEV acceptance as a mainstream vehicle is the direct impact that the use of electricity as a transportation fuel would have in reducing the use of petroleum for transportation. Since very little oil is used to produce electric power in the U.S. today (and even less is expected to be used in the timeframe of this study), the use of electricity as a transportation fuel by the PEV represents a reduction in the use of oil.

Transportation represents the largest user of petroleum in the U.S. economy: $70 \%$ of U.S. oil consumption goes to transportation. PEVs that fully or partially operate on electricity directly reduce the need for imported oil. Oil imports represent over $40 \%$ of the U.S. international balance of payments trade deficit. No other single aspect of the economy represents a larger opportunity to reduce the trade deficit than the use of petroleum for transportation. The widespread adoption of PEVs as a mainstream vehicle represents the largest single opportunity to reduce that deficit, which helps to achieve a major U.S. public policy economic goal.

By extension, the reduction in the use of petroleum for transportation by replacing it with the domestic energy sources used to produce electricity not only reduces the U.S. trade deficit, it also reduces U.S. dependence on foreign oil, supporting public policy national security objectives.

Finally, widespread, mainstream adoption of PEVs has the potential to reduce tailpipe emissions of greenhouse gasses (GHGs). The Sentech study of which this report is a part demonstrated that the use of electricity as a transportation fuel for PEVs can produce a net reduction in GHG emissions, relative to comparable conventional vehicles, in regions that have low-carbon 
generation mixes. As the U.S. generating mix changes to cleaner forms of generation through increased use of renewable sources, nuclear power or cleaner, and the transition to more efficient coal plants (while displacing and retiring older, less efficient units), the net reduction in total GHG production by the transportation sector is further increased.

On balance, the contribution of PEV adoption to the public policy objectives evaluated in this study was rated as producing medium to high public sector benefits.

\section{Risks to the Public Sector}

Achieving public sector public policy objectives by achieving a sustainable PEV market in a timely manner requires that the major impediments to commercial and technical PEV success must be overcome, and overcome in a timely manner. Figure 10 illustrates the team's evaluation of the principal risks to achieving public policy benefits that stem from reaching a sustainable PEV market that come from public sector actions.

Figure 10: Public Sector Risk Analysis

\section{GOVERNMENT RISKS}

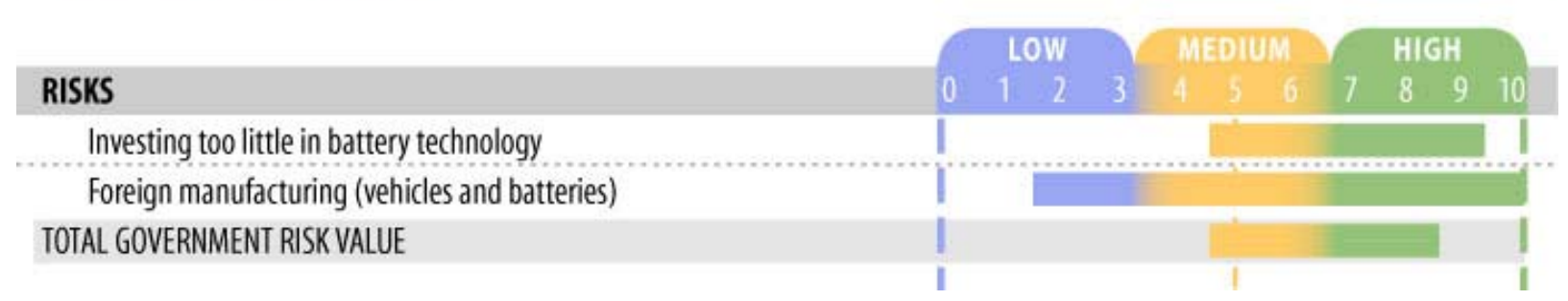

The discussion of the technical and commercial challenges the OEMs face in achieving PEV success identified the most important factors influencing that success from their OEM perspective. As noted, the major technical challenges revolve around battery development issues, principally battery energy density, cycle life, reliability and overall production cost/performance.

The assessment team believes that the major opportunity for public sector contributions to overcoming these battery-related issues stems from public sector support of battery-related research and development. That is especially true in the case of the relatively young stage of development of lithium-ion battery technology, and the opportunity for cost reductions based on economies of scale in production. It is also important to fund research on battery chemistries beyond lithium ion. It is possible that some of the properties that will add significant value in the PEV application may be more attainable with other chemistries. Care should be taken to assure adequate funding for next generation battery technology, rather than on incremental improvement to current-generation batteries.

As a result, the risk-assessment results for the public sector in Figure 10 show a relatively high level of risk that there will be too little investment — public and private - in battery technology development, in battery R\&D. 


\section{OVERALL RISK/BENEFIT CONCLUSIONS}

The final task of this effort was to combine the insights developed from the interviews with the participants from all three sectors-OEMS, utilities, public sector - and the analysis of those results into an overall assessment of the challenges to successful transitioning of commercial PEV deployment from the early adopter stage through a transition to a stable, sustainable mainstream market.

The following discussion provides the conclusions that the project team believes should be drawn from each of the three stakeholder segments, and then the major bottom line conclusions that can be drawn from the overall assessment.

\section{Conclusions: The OEM Perspective}

The overall conclusion to be drawn from the Risk/Benefit assessment by the OEM participants is that the OEM community is optimistic that PEVs will become a significant mainstream vehicle within the timeframe of this study. As illustrated in Figure 11, they perceive the value proposition - the benefits of PEVs to their market - to be relatively high, and they perceive both the technical risks and the commercial/business risks to be moderate and manageable.

Figure 11: OEM Risk/Benefit Analysis

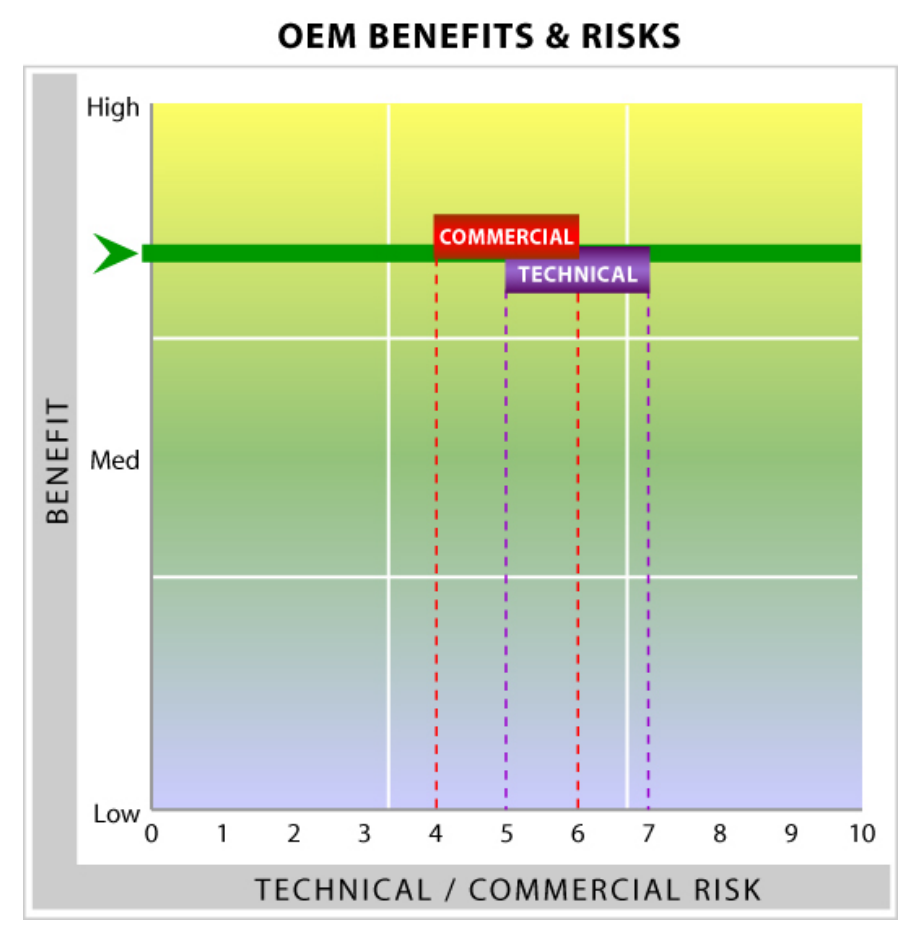

On the benefits side, the results of the project team's interviews with the OEMs summarized in the previous chapter found that the PEV is likely to be moderate to highly beneficial to them as a vehicle that meets customer expectations with regard to overall economics and performance, while at the same time making a positive environmental and public policy contribution. 
From their own perspective, the OEMs saw moderate to high contributions to their own fuel economy and emissions requirements, as well as meeting anticipated ZEV requirements. They believe that PEVs will provide them with vehicles that will help them meet the objectives set out for them by these highly visible, public-policy driven requirements. Since other OEMs that have PEV platforms in their vehicle fleets will be able to use the PEVs in meeting those requirements, over time it becomes almost a competitive requirement for virtually every major OEM to include PEVs in their fleet.

On the risk side, the OEMs perception of both the technical and commercial risks to achieving a sustainable PEV market to be generally moderate and manageable in the timeframe of this study. The most important sources of technical risk in their assessment were the factors affecting the cost and performance of the PEV battery technology, from energy density to production costs to battery degradation over time. In addition to battery issues, the OEMs also saw technical risks coming from their ability to make progress with regard to the electronic components of the vehicle, and to improve the efficiency (and hence battery energy consumption) of the vehicles passenger comfort systems. Comfort system efficiency improvements are in their view more significant for the PEV than they have been for the traditional ICE drive train platform.

Although not called out in the assessment, for similar reasons several of the OEM participants also pointed to the value of overall improvement in vehicle weight, producing a vehicle with greater efficiency and greater battery mileage.

On the commercial side, the OEMs saw the greatest source of risk coming from the ability to achieve overall vehicle performance expectations, and the potential for significant improvement in competing vehicle technologies, especially the HEV.

What is striking in the OEM perspective is that there is little difference between their perceptions regarding the relative magnitude commercial versus technical risk. The OEMs saw little difference between the two. In their view, if the technical risks can be overcome, they will be able to deliver a vehicle that meets market expectations, moderating the scale of commercial risk. 


\section{Conclusions: The Utility Perspective}

The overall conclusions to be drawn from the utility assessment was that utilities generally see significant benefits deriving from the PEV, and saw little or only moderate technical risk in the timeframe of this study.

Figure 12: Overall Utility Risk/Benefit Analysis

\section{UTILITIES BENEFITS \& RISKS}

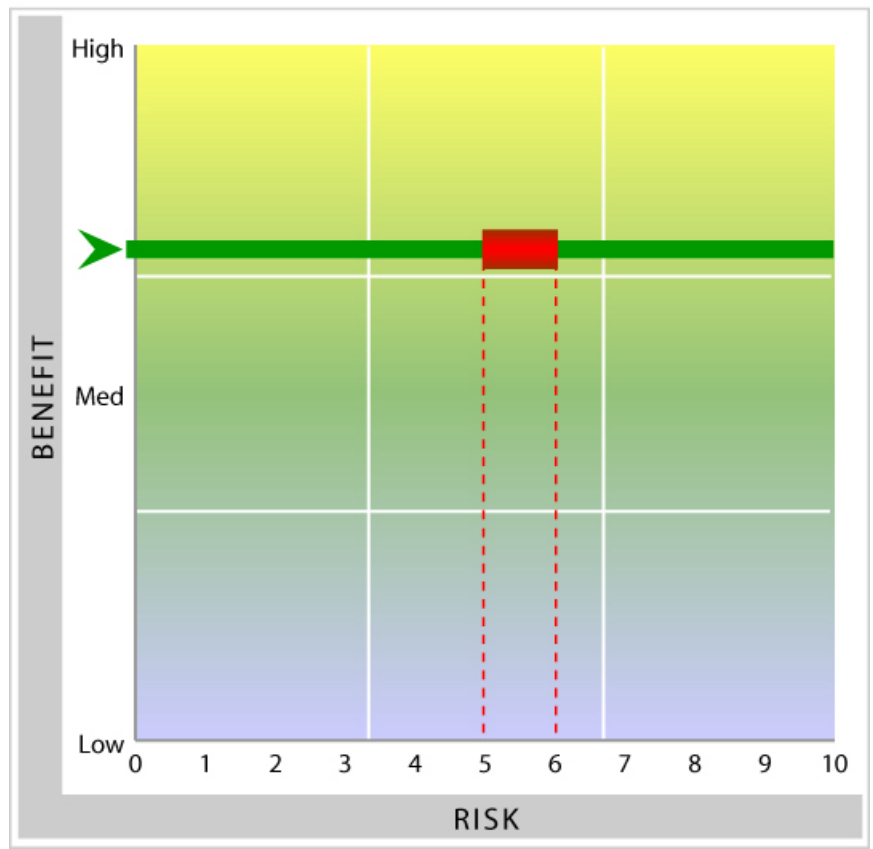

On the benefit side, the utilities participating in this study saw high or moderate-to-high benefits deriving from the operating improvements they anticipate from improved asset utilization that will come from improvements to their load curve from night time charging, and from what they expect to be a more controllable load. The participants also saw significant benefits from the compatibility of PEV charging with wind-based renewable generation. For most of the utility systems participating in this study, the pattern of evening and night charging coincides well with wind generation, which often peaks at night. The resulting compatibility will contribute to the ability to absorb higher levels of wind generation on the system.

On the risk side, the utilities saw only moderate risks to successful PEV implementation. They generally commented that by the timeframe under consideration for the transition from early adopters, they believe that the process of building out the infrastructure investments needed to upgrade local circuits for PEV service will be well in hand, and any risks of distribution system reliability will have been mitigated.

Four other conclusions that emerged from the utility part of the study are worth noting. First, the utility participants generally do not see V2G emerging as a significant option during this time window. Second, they generally agreed that "smart grid" technology is not necessary for successful PEV deployment. They noted that where "smart grid" technology was in place, it 
would to be quite helpful in managing and coordinating PEV loads, but it was not a necessary requirement.

The third observation is that load management of the PEV load realistically requires Level 2 charging $(240 v)$ to be successful and valuable. The utility participants generally felt that demand for PEVs at the mainstream level will increase the demand for Level 2 charging systems, with all of the implications for increasing the potential for load management that that implies.

Finally, it is worth noting that there is a different perspective among distribution utilities than among transmission system managers. Based on earlier Taratec work, from a transmission perspective, the major interest is in the ability to "shut off" a load to meet peak service needs at a regional level. By contrast, the distribution utility has a strong interest in true load management/load control - the ability to move the timing of individual PEV charging to meet very localized needs, possibly including optimizing the ability to absorb additional renewable generation, which is very time-specific.

\section{Conclusions: The Public Sector Perspective}

The overall conclusions from a public sector perspective were actually quite striking. From the standpoint of achieving public policy objectives and contributing to public policy interests, the benefits to be derived from achieving mainstream success for PEVs are the highest of any of the three stakeholder groups, while the challenges and risks of achieving those objectives are also generally higher than for any other stakeholder sector.

Figure 13: Overall Pubic Sector Risk/Benefit Analysis

GOVERNMENT BENEFITS \& RISKS

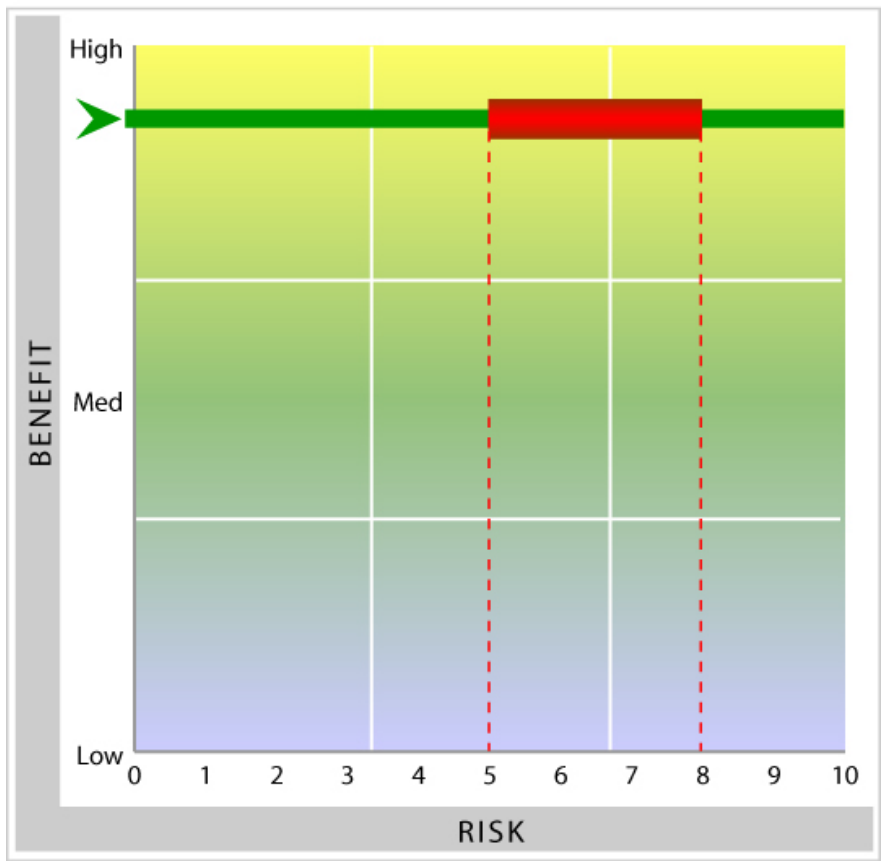

On the benefits side, PEVs have the potential to make major contributions to the policy agenda considered in this study. In particular, mainstream adoption of PEVs can make significant 
contributions to balance of trade improvement through oil import reduction, perhaps becoming the biggest source of improvement to both the reduction of oil imports and to balance of trade economics. Similarly, that oil reduction in trade for increased use of domestic energy sources for electric generation also contributes to reducing foreign oil exposure, enhancing the U.S.'s national security agenda.

Finally, the reduction or elimination of tailpipe emissions of GHGs contributes to public policy environmental goals, an improvement that grows over time as the sources of power generation in the utility industry change. The changes in the sources of generation to increased use of renewables and nuclear power, as well as cleaner coal generation, are likely to make future GHG improvement from mainstream PEV adoption even greater.

On the risks side of public policy interests, the most significant risks were perceived to be inadequate investment in advancing battery technology, losing the opportunity to take advantage of that market and the economic value that goes with it for domestic producers - and possibly slowing the pace of improvement in PEV battery technology overall. The second source of risk was perceived to be the failure to take advantage of PEV manufacturing opportunities for domestic production of both vehicles and batteries.

Both of these risks were felt to be amenable to public policy solutions.

\section{Conclusions: The Bottom Lines}

Five overall observations stand out from this study:

1. While the benefits perceived by all three stakeholder participants were generally high, the overall risk was perceived as only moderate in character by all three. Each sector perceived the factors that shaped risks to PEV success as manageable over the timeframe of this study.

2. The OEMs in particular perceived both the technical and commercial risks of achieving mainstream PEV success to be moderate throughout. They believe that the risk of achieving the technical advances necessary to make the PEV platform attractive to the mainstream market to be moderate and manageable in this timeframe. As a result, they also see the commercial risks as moderate - and in fact slightly lower than the technical risk.

3. The OEMs believe that the attributes of electric vehicles provide important benefits in meeting public policy-driven regulatory requirements (e.g., standards for fleet GHG and other emissions, fuel economy, ZEV). Achieving mainstream market success will facilitate meeting those requirements - making it almost a necessity for each individual OEM to have PEV platforms in their mainstream market offerings.

4. The combination of high benefits to all stakeholders and moderate-to-high and very focused risks are the "sweet spot" for public/private collaboration. It is generally argued that the private sector is the appropriate party to bear responsibility for funding development of low risk technology or technology with only low, incremental benefits - the left and bottom portion of Figure 14. In contrast, the proper role of the public sector is to invest collaboratively with the private sector in technologies with higher risk and higher benefits, especially public policy benefits - the shaded, upper right hand quadrants in Figure 14. 
Figure 14: Public-Private Technology Collaboration

PUBLIC - PRIVATE COLLABORATION

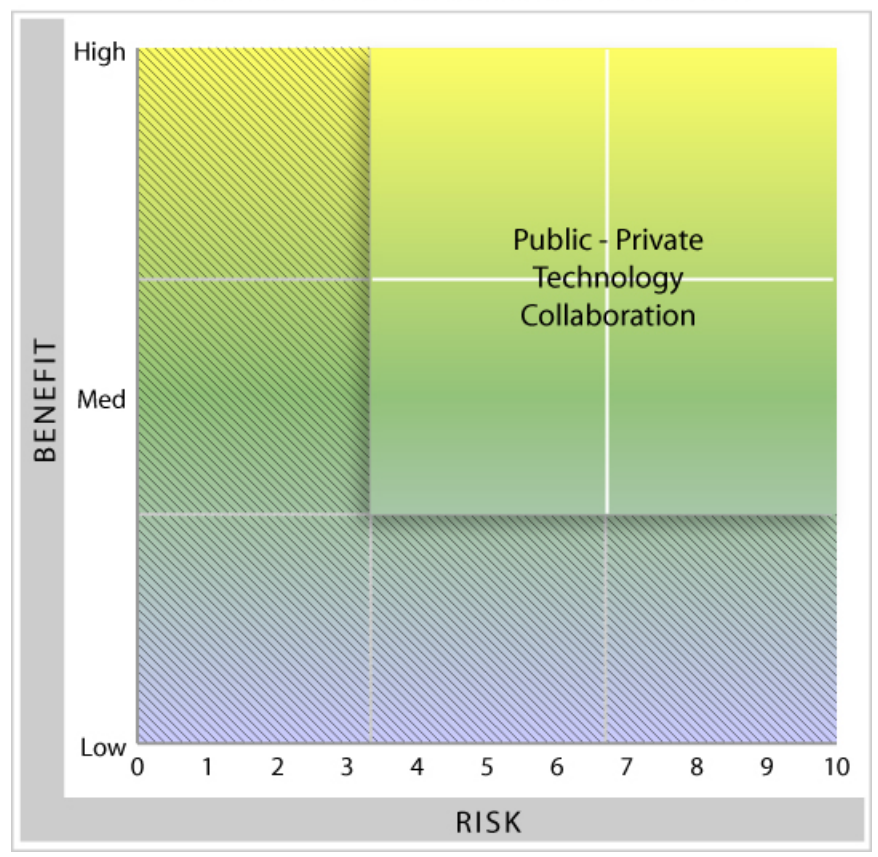

5. Both OEM-related and utility-related technical and commercial factors influence mainstream success for PEVs. It is important that the public sector collaboration be directed to both sectors, and that it be focused on those factors that the participants perceive to have the most important influence on PEV success. 


\section{RECOMMENDATIONS}

Based on the results of this study and the overall conclusions enumerated in the preceding chapter, several strong recommendations emerge. All three stakeholders derive significant benefit from the success of the PEV platform. Both the auto and utility industries and the public sector have a significant stake in the success of the PEV platform in moving from the early adopter into the mainstream market.

The relationship of high public and private benefits to moderate-to-high OEM risks found in this study is the "sweet spot" for public/private collaboration in non-proprietary technology development. There are a number of initiatives that the DOE can undertake or continue that have the potential to reduce the risks associated with making the PEV platform a mainstream consumer vehicle. These initiatives are consistent with both current and prior DOE programs.

\section{Vehicle Technology Advancement}

1. Advanced battery technology:

- Much of the technical risk associated with PEV development relates to battery costs and performance issues. Continued DOE support for battery development is appropriate as a public-private collaboration. That support should be focused on areas identified as particularly important by the OEMs in this study. Those factors generally affect the number of miles the batteries provide, the cost of battery production, and overall battery life.

- Battery technology continues to advance quite rapidly. DOE funding should be focused on a continuously moving target —on advancing the next generations of batteries - rather than on a static, long run target.

- The needs of the PEVs are specific to each individual platform - to the design, class and weight of the individual platform, ranging from EREVs to BEVs to PHEVs. The needs are specific, and they are also changing. DOE battery technology funding support should be specific and changing, reflecting the varied needs of the several platforms, and the continuous improvement that characterizes battery technology development. DOE funding should not be limited to lithium ion chemistries: other chemistries may well turn out to be better suited to the range of properties appropriate to PEV application across the broad fleet of PEV platforms likely to emerge.

- Other technical characteristics of battery technology also provide opportunity to make PEVs attractive to the mainstream market. Some of the attributes of PEV battery technology represent areas where longer-run DOE research efforts are likely to be required. Advances that would significantly enhance the attractiveness of PEVs to the mainstream consumer include the speed with which recharging can be delivered, the optimization of battery cell operation to extend the mileage available from a given energy density, and the depth of discharge that can be obtained from the battery cells. 
- The PEV technology platforms already announced by the OEMs incorporate a range of platforms and vehicle classes in the PEV fleet, including BEVs and EREVs, as well as PHEVs. Each platform type and vehicle class is likely to have a different battery design specific to its requirements. The focus of the modeling and analysis of the Sentech study has been PHEVs of a specified size class. (Note that the PHEVs included in the Sentech study included both series and parallel PHEVs.) To support the design of an effective advanced battery R\&D program, DOE should expand the scope of the modeling of the Sentech study to cover the broader array of platforms and sizes that will make up the range of the PEV fleet in this timeframe, in order to fully understand the battery requirements of this range of vehicle types.

2. Other areas of the PEV technology

- Other areas of PEV vehicle technology are also important to PEV success. PEVs have very specific advanced electronics. Power electronics represents an area of technology that continues to be rapidly advancing. This area also represents an area where technology advancement offers a real opportunity to support domestic U.S. technology leadership. DOE funding support of private sector technology advances and the integration of those advances into PEV systems represents a significant opportunity to advance PEV technology into the mainstream while at the same time supports an important source of the benefits to the public sector identified in this study.

- Other candidates for public/private collaboration are not specific to the PEV platform and would improve performance of all classes of vehicles. Many of those areas of general vehicle technology are particularly important to PEV success in that they directly affect the mileage available from a given battery size and energy density. DOE funding support of advances in other areas of vehicle technologies not limited to $P E V S$ such as passenger comfort system technology, regenerative braking and vehicle materials that ultimately affect vehicle weight present excellent candidates for public-private collaboration.

The design of the Sentech research funded by DOE was based on the results of a workshop held in December 2007. The workshop included 120 industry participants, and was intended to provide guidance on the potential value propositions that could lead to a sustainable market for what were expected to be grid-connected, plug-in hybrid electric vehicles. At the time of that study, the PEV platform that appeared most likely to be viable was the PHEV. As the stream of announcements summarized in the appendix to the main Sentech study report indicates, we now expect to see a vehicle fleet made up of a variety of different PEV platforms covering a full range of vehicle types and classes. PHEVs may well become a minority of the PEVs on the road in the timeframe of this study, and no PEV platform is likely to dominate the fleet. The value proposition that is likely to emerge is likely to be significantly different than was envisioned at the time of the December 2007 workshop. First and foremost, it is likely to be characterized as a true fleet - an array of vehicle types and platforms, each with its own design, characteristics and value proposition.

In order to understand both the contribution to the several value streams and to public policy goals, it is necessary to understand and evaluate the characteristics of the emerging PEV fleet as 
a fleet. Recognizing the fleet characteristics that will likely emerge over time, and modeling the fleet appropriately, would help in designing the technology development initiatives that will best enable the transition of the vehicle to a commercially viable, sustainable mainstream market.

Two specific recommendations emerge from the discussions with the industry and public policy participants in the Taratec/CAR portion of this study:

3. Vehicle fleet analysis and modeling

- ANL's PSAT model was used in Sentech's comprehensive study to provide a rich set of insights for the drive cycle characteristics of the three vehicle platforms - ICE, HEV, and PHEV - that were investigated. ANL's GREET model was also used to capture W2W greenhouse gas emissions performance for these three vehicle platforms, and the Ohio State University Center for Automotive Research's battery estimation model was used to predict the life of batteries under different levels of stress. Given the significant differences among the various PEV platforms and vehicle types that will make up the fleet, it is likely that a broader modeling effort will yield results that are different from those of the three vehicle platforms. $\boldsymbol{D O E}$ should fund additional modeling and analysis from a broader spectrum of PEV platforms and vehicles classes to better understand the broader value proposition the fleet is likely to provide.

- To provide more contemporary guidance for the value proposition study - and in particular to provide clearer insights regarding the likely characteristics of the PEV fleet as it evolves, DOE should consider funding a second advisory workshop. The workshop should include a diverse set of industry participants knowledgeable of the current state of PEV planning.

The participating distribution utilities commented on the potential - and even likely - emergence of "hot spots" (i.e., concentrations) of PEV adoption. These concentrations of PEV loads on individual circuits and transformers could result in specific areas that require distribution circuit upgrades to maintain reliable service. Utilities expressed the concern that without adequate information about where the newly purchased PEVs are located, they will find it difficult to identify these rapidly emerging points of concentration of PEVs where infrastructure upgrades may be required, potentially compromising their ability to serve the charging load reliably. Utilities also believe that the ability to control charging loads in terms of load levels and timing is important to their success in maintaining high quality reliability as the PEVs enter the market. Both technical and operational advancements would enhance mainstream public acceptance of PEV technology.

4. Utility Infrastructure Reliability Support

- Utility ability to gain notification of new PEV customer locations may be limited due to privacy concerns, but is important to make sure that local circuit and transformer infrastructure is adequate to meet PEV charging needs. Public sector assistance in generating information about the locations of PEV deployment would help mitigate this early stage impediment to moving through the transition to a sustainable mainstream market. DOE should work with the OEMs, dealers and Federal and 
state public policy makers to develop information systems that provide timely information to utilities about new PEV locations. It is anticipated by utilities that this information flow will become less important over time as their data, modeling, information systems and system upgrades improve.

- The distinction between OEM industry organization (national) and utility organization and issues (highly regional) implies an opportunity to organize Federal government efforts in support of infrastructure development or public demonstration on a regional basis. To the extent that infrastructure approaches and systems can become uniform across the country, OEMs will find it easier to market PEVs, and consumers will find it easier to obtain the equipment they need simply and in a timely manner. DOE should continue to sponsor regional demonstrations of $\mathrm{PEV}$ installation and operation designed to develop the information and processes that OEMs, utilities, regulatory bodies and consumers need to facilitate PEV ownership and operation.

\section{Utility Distribution Infrastructure Technology Advancement}

- Utilities believe that the ability to manage and control PEV charging loads will mitigate some of the need for local infrastructure upgrades, and will increase their ability to provide assured, reliable energy delivery. Advances in load management technology and information systems will permit greater load management capability in the future, enabling PEVs to become established within the mainstream market. Working with utilities and private sector technology developers, DOE should support continued development and demonstration of the charging system load management technologies and information infrastructure necessary to support PEV charging. DOE should also support and encourage the private sector development of standardized charging system technology. 


\title{
Appendix
}

\section{Industry Participants}

The sector assessments involved in this study were conducted using open-ended interviews with representatives of selected auto industry and utility industry companies, and with a Federal government transportation policy executive, recently retired. All interviewees were promised personal confidentiality.

The companies that participated in the study were:

\section{Automotive industry OEMs}

Ford

General Motors

Nissan

Toyota

\section{Utility industry distribution companies}

\author{
American Electric Power \\ Consolidated Edison Company of New York \\ DTE Energy \\ Duke Energy \\ San Diego Gas \& Electric (Sempra Utilities) \\ Southern California Edison
}

